\title{
Model of facilitation of emotional intelligence to promote wholeness of neophyte critical care nurses in South Africa
}

\author{
A. Towell ${ }^{a, *, 1}$, W.E. Nel ${ }^{b, 1}$, A. Muller ${ }^{b, 1}$ \\ a School of Nursing and Midwifery, Edith Cowan University, Western Australia, Australia \\ ${ }^{b}$ Department of Nursing Science, University of Johannesburg, South Africa
}

\section{A R T I C L E I N F O}

Article history:

Received 16 February 2015

Accepted 24 February 2015

Available online 14 April 2015

\section{Keywords:}

Emotional intelligence

Wholeness

Resilience

Facilitation

Critical care nursing

\begin{abstract}
A B S T R A C T
This study was undertaken in order to develop a model of facilitation of emotional intelligence to promote wholeness in neophyte critical care nurses in South Africa. A theorygenerative, explorative, descriptive, contextual research design was used. The model was developed utilising the four steps of theory generation as proposed by Dickoff, James, and Wiedenbach (1968), Chinn and Kramer (2011) and Walker and Avant (2011). Step one dealt with the empirical phase in which the concepts were distilled. The facilitation of inherent affective and mental resourcefulness and resilience was the main concept of the model. Step two comprised the definition and classification of central and related concepts. Step three provides a description of the model. The model operates in three phases namely the dependent phase, partially dependent phase and the independent phase. Step four entailed the description of guidelines for operationalizing the model. During the three phases of the model a new nurse who starts to work in critical care moves from a latent ability to develop an inherent affective and mental resourcefulness and resilience to a state of developing an inherent affective and mental resourcefulness and resilience. This model provides a structured framework for the facilitation of emotional intelligence (EI) to promote wholeness in nurses who commence to work in critical care units.
\end{abstract}

Copyright $\odot$ 2015, Production and hosting by Elsevier B.V. on behalf of Johannesburg University. This is an open access article under the CC BY-NC-ND license (http:// creativecommons.org/licenses/by-nc-nd/4.0/).

\footnotetext{
* Corresponding author.

E-mail address: a.towell@ecu.edu.au (A. Towell).

Peer review under responsibility of Johannesburg University.

${ }^{1}$ Authorship contributions were divided equally. http://dx.doi.org/10.1016/j.hsag.2015.04.001
}

1025-9848/Copyright @ 2015, Production and hosting by Elsevier B.V. on behalf of Johannesburg University. This is an open access article under the CC BY-NC-ND license (http://creativecommons.org/licenses/by-nc-nd/4.0/). 


\section{What is already known about this topic?}

- There is a large amount of literature and research surrounding emotional intelligence.

- It is known that emotional intelligence can be improved.

- Having an improved level of emotional intelligence can help an individual effectively manage with stress and burnout and difficult situations at work.

- There is little known regarding the development of emotional intelligence in critical care nurses.

\section{What this paper adds}

- This paper describes the methodology of the development of the model for the facilitation of emotional intelligence of critical care nurses in South Africa.

- This paper describes the model in detail.

"Comfort in expressing your emotions will allow you to share the best of yourself with others, but not being able to control your emotions will reveal your worst." (McGill n.d.).

\section{Introduction}

The critical care unit is known to be a high-stress environment and nurses working in these units are faced daily with difficult situations and critically ill patients. The nurses are confronted by the emotional and physical pain that is experienced by patients and their families, stress from the work environment, and exposure to difficult ethical decisions such as withdrawal of treatment (Meltzer \& Huckabay, 2004). The stressors experienced by nurses in critical care units could lead to a nurse displaying signs of stress, stress-related illnesses, emotional labour burnout, depersonalisation, feelings of failure, demotivation, conflict with other staff members and even leading to a decrease in providing quality patient care (Poncet et al., 2007). These signs indicate that the body, mind and spiritual dimensions of the nurse are not equal or whole. This can lead to the nurse being unable to function optimally in a high stress environment (Newman, 1994). Individuals with a higher level of emotional intelligence (EI) have decreased levels of stress and higher levels of perceived control, satisfaction and commitment (Petrides \& Furnham 2006).

Emotional intelligence refers to the ability to identify, express, understand and regulate emotions either negatively or positively in oneself and in others (Matthews Zeidner \& Roberts 2004). According to the Trait Emotional Intelligence Research Program (2001), trait EI consists of four factors. The first factor is a sense of well-being and comes from past achievements and extends into future expectations. The second factor is self-control, which is the ability to have good control over urges and desires, to have the ability to fend off impulses and to be able to regulate external pressures and stress. The third factor is emotionality, which relates to the ability to perceive and express emotions and then to be able to use this skill to develop and sustain relationships. The final factor is sociability which has its focus on the individual in various social contexts rather than on personal relationships that emphasises social relationships and social influence.

Nurses with high EI utilise various methods to manage their emotions and stress. Work-related EI is a crucial attribute in negotiating the demands, constraints and opportunities necessary to be able to succeed in the workplace (Matthews, Zeidner, \& Roberts, 2004; Vitello-Cicciu, 2003). Kooker, Shoultz, and Codier (2007), posit that applying EI frameworks that could contribute to wholeness within nursing practice could identify factors that might lead to improved nurse retention and patient outcomes.

Attention therefore needs to be paid to the EI of nurses to equip them with the ability to be able to look after themselves as a whole person, with equal body, mind and spiritual dimensions, as well as to be able to nurse and care for the patient holistically. According to Kaur, Sambasivan, and Kumar (2013), the caring behaviour of nurses contributes to the satisfaction experienced by patients, their well-being and subsequently to the performance of staff in the health care organisation. Kaur et al. (2013), believe that the caring behaviour of nurses is influenced by physiological, psychological, socio-cultural, development and spiritual factors. These factors relate to the wholeness of the nurse. Little research has been done on the EI of critical care nurses in South Africa and how to promote it, this article hopes to add to the body of knowledge. The research question that therefore arises is: How can the EI of registered nurses be facilitated to promote wholeness in the neophyte critical care nurse? The purpose of the study was to develop and describe a model of EI to facilitate the wholeness of the neophyte nurse in critical care units in South Africa.

\section{The process of theory development}

The four steps of theory generation, namely, the distilling of concepts; defining and classification of the central concepts: description of the model and the evaluation and implementation guidelines of the model were used in the theory. The model was developed by using the steps of theory generation as proposed by Dickoff, James, and Wiedenbach (1968), Chinn and Kramer (2011) and Walker and Avant (2011). The format of this article will follow the four steps of theory generation.

\subsection{Distilling of concepts}

Distilling of concepts was accomplished by the empirical phase of the study of which the main objective was to investigate the global EI of registered nurses working in critical care units in South Africa, as well as to investigate if there was a difference in the EI score of the critical care nurses that work in the various speciality areas of critical care (called context groups) each with their different stressors (Towell, Nel, \& Muller, 2013). 
The research design used for this was a typical quantitative, descriptive survey, explorative and contextual design. The main concept was distilled from the results obtained from the TEIQue-SF questionnaire/survey which measures the global emotional intelligence.

Ethical clearance was obtained from various parties (University of Johannesburg [Higher Degree and Ethics Committee], Dr Petrides and the Critical Care Society of Southern Africa) prior to conducting this research. The ethical clearance number is AEC58/09, the Higher Degrees clearance is HDC55/ 2009 and clearance letters were received from the Critical Care Society and Dr Petrides.

This questionnaire is a standardised measuring instrument with proven validity and reliability with the Cronbach's alpha measuring 0.88 (Petrides, 2006). The TEIQue-SF questionnaire consisted of 30 questions that the respondents could answer on a likert scale measuring global trait EI. Convenience sampling method was used to recruit all registered nurses that attended a Critical Care Congress. The inclusion criteria were that the respondents had to be a registered nurse, had worked or were still working in a critical care unit. The respondents held a variety of job descriptions in both the private and public health sector. Registered nurses in South Africa often work overtime or agency/sessional work in both private and public hospitals. Any potential respondent that did not meet the inclusion criteria was excluded. The total registered nurses attending the congress was $N=380$, a total of $220(n=220)$ questionnaires were completed and returned which gave a response rate of $58 \%$.

Descriptive statistics were calculated for biographical variables, mean total EI and subscale scores. The Kolmogorov-Smirnov test for normality was used to determine whether the variance between the context groups being compared was equal or not. The next stage in analysing the data involved the use of comparison t-tests. The data were also analysed using an oneway analysis of variance (ANOVA). In all of the various context groups, the $p$-values in the t-tests were $>0.05$, which means that the null hypothesis that there was no statistically-significant difference between the EI of critical-care nurses in South Africa in the various context groups was accepted. The EI mean score of the critical care nurses was 155.98 which was indicative of a higher range of emotional intelligence (Towell et al., 2013).

The next step in the data analysis involved an exploratory factor analysis, which identified eight factors as having eigenvalues greater than one, and the statistical evidence pointed to concentrating on factors numbered one and two. Factor one had nine items loading on to it and factor two had 5 items loading on to it. The remaining factors had three or less items loading on to them, thus making only factor one and two significant.

The main concepts were distilled from the factor analysis. Items that loaded onto factor one were expressive as personality traits and pointed to a positive outlook, optimism and inner strength. The items that loaded onto the second factor were also expressive as personality traits but were perceived as the challenges that the critical care nurses face. Overall the main concept that was distilled from factor one and two was an affective and mental resourcefulness in which critical care nurses cope very well and are resilient to the types of challenges they face on a daily basis. Pragmatically these two factors became the focus of the model, as they formed the central essence of EI of the critical care nurses. The main concepts that were distilled were facilitation of inherent affective and mental resourcefulness and resilience.

The main concept and related concepts were identified from the empirical phase. They were classified using the survey list as proposed by Dickoff et al. (1968). The list consists of six items which include: the agent, recipient, context, procedure, dynamics, context and terminus, and are described as follows:

- The agent is the person who performs the activity. In this model the agents are mature critical care nurses, who have broad experience in the different fields of critical care, as well as in the internal environment of the critical care settings. They are independent practitioners and are capable of critical thinking. The agents have a tested resourcefulness and resilience, as they have a wide range of experience and knowledge.

- The recipient is the person(s) receiving the activity. In this case the recipient is nurses who are just entering the critical care environment. They are unaware of the unique internal environment and the type of patient they may be nursing within the unit, as well as how this may impact on their own internal dimension. They are dependent on the agents because their ability to think critically and independently has not yet been developed. The recipients also have the ability and the motivation to learn. They have an untested resilience and a latent resourcefulness that with time and facilitation can be developed.

- The context refers to the environment in which the activity is performed. In this case the context is the various critical care units throughout South Africa, in either a private or public hospital.

- The terminus is the outcome. In this model the outcome will be an affectively and mentally resourceful and resilient critical care nurse who continually strives for personal wholeness.

- The procedure refers to how the activity takes place. The procedure for this model takes place along a continuum and involves dynamic interaction between the agents and the recipients.

- There are two dynamics that serve as an energy source and drive for this model. The first is the neophyte nurses' desire to improve - their quest for wholeness. They have an eagerness to learn, a desire to be highly skilled and knowledgeable. The second dynamic comes from the health institutions in both the private and public healthcare facilities. Both services have a desire and a drive for quality patient care and to decrease sentinel events, as these place their reputation at risk as well as increase the chance of legal action against them.

The attributes and characteristics of a concept are examined through the strategy of concept analysis. Chinn and Kramer (2011), state that defining concepts and reading as much as possible is invaluable for the development of a model. However in this study, the concept facilitation of inherent affective and mental resourcefulness and 
resilience was defined and described, by commencing with the individual concepts, namely "facilitation", "inherent", "affective", "mental", "resourcefulness" and "resilience". Various dictionaries, subject textbooks, database (Medline, EBSCOhost, PubMed and Proquest) and peer-reviewed journals were read extensively to understand the identified main concepts.

Once all the different definitions of the concepts were examined, a list of essential and related attributes was identified. This step was necessary to identify, analyse and synthesise the attributes for the definition of the main concepts.

After the construction of the model had been finalised a list of the central and related concepts were developed, so that the concept of EI could be defined within the context of the study.

The identified, essential, related attributes of the concept of "inherent affective and mental resourcefulness and resilience" are reflected upon. The attributes were then used to construct the relationship statements.

Facilitation of inherent affective and mental resourcefulness and resilience involves an enabling improvement in a supportive climate. A facilitator helps individuals to accomplish their goals, which takes place in an open learning climate. It is a conscious dynamic and interactive process that takes place over time. The facilitator mobilises resources to enable improvement at a mental, emotional, spiritual and physical level. Every individual has a pre-existing inherent potential which can be developed through emotional learning. The potential is essentially a natural ability. Emotional responsiveness can be observed by others. It is the outward manifestation of emotion, feeling or mood and is termed affect. People can see the affect through body language. To be able to reason about what is known and what can be observed involves being able to reason critically. It involves being able to intelligently process solutions to problems and then to evaluate those solutions. People learn and are taught how to adapt and to become resourceful. They develop a set of selfcontrol skills or abilities that allows them to exhibit flexibility and resilience. They use these skills in order to bounce back, and use these experiences to survive, recover and to grow. The development of inherent affective and mental resourcefulness and resilience will help with the facilitation of EI" (Towell et al., 2013).

The identified essential and related attributes were then used to construct relationship statements described below.

\subsection{The construction of relationship statements}

According to Walker and Avant (2005), concepts are building blocks of a theory and they are held together by the relationship statements. Concepts that have been identified, defined and classified in this study were then placed into relation to each other, through the use of relationship statements. The following relationship statements have emerged from the concepts for this model:

- The process of facilitation of EI starts when the neophyte nurse forms a relationship with the facilitator, other healthcare team members and different individuals within the healthcare setting.
- The facilitator renders support by implementing resources to support the nurse such as emotional, instrumental, informational and educational.

- The facilitator arranges for resources to be implemented for the facilitation of the EI of the nurse. This can take the form of formal/informal instruction to teach problemsolving skills, abstract thinking, reasoning skills, reflective thinking, critical thinking and positive selfinstruction.

- These resources should be seen as improving the EI and developing the affective and mental resourcefulness and resilience of the nurse.

The relationship statements help to give the concepts clarity and add direction to the understanding of the phenomenon.

\subsection{A description of the model}

An overview of the model will be discussed, followed by a description of the structure, structural description and the process of the model.

\subsection{An overview of the model}

Emotional intelligence contributes to wholeness, according to the Theory for Health Promotion in Nursing (University of Johannesburg, Department of Nursing Sciences, 2009), and the individual has an internal dimension that is made up of the intellect, emotion and will. The critical care nurses need to pay attention to their wholeness in order to be able to equip themselves as a whole person with balance between body, mind and spiritual dimensions, so as to be able to nurse the critically ill patient as a whole being.

Fig. 1 depicts the facilitation of inherent affective and mental resourcefulness and resilience in registered nurses that commence work in critical care units in either a public or private health institution in South Africa. The model has three phases: phase one, the dependent phase; phase two, the partially dependent phase and the final phase three which is the independent phase. It involves an interactive process between the agent (the mature and experienced critical care nurse) and the recipient (the new nurse starting work in a critical care unit) and it takes place along a continuum. The recipient moves through the three phases with subtle graduation between the phases and the pace of the movement depends on the individual recipient. The whole process contributes to the development of the facilitation of inherent affective and mental resourcefulness and resilience of the recipient.

\subsection{The structure of the model}

The components of purpose, assumptions, context and theoretical definitions are addressed in describing the structure of the model. 


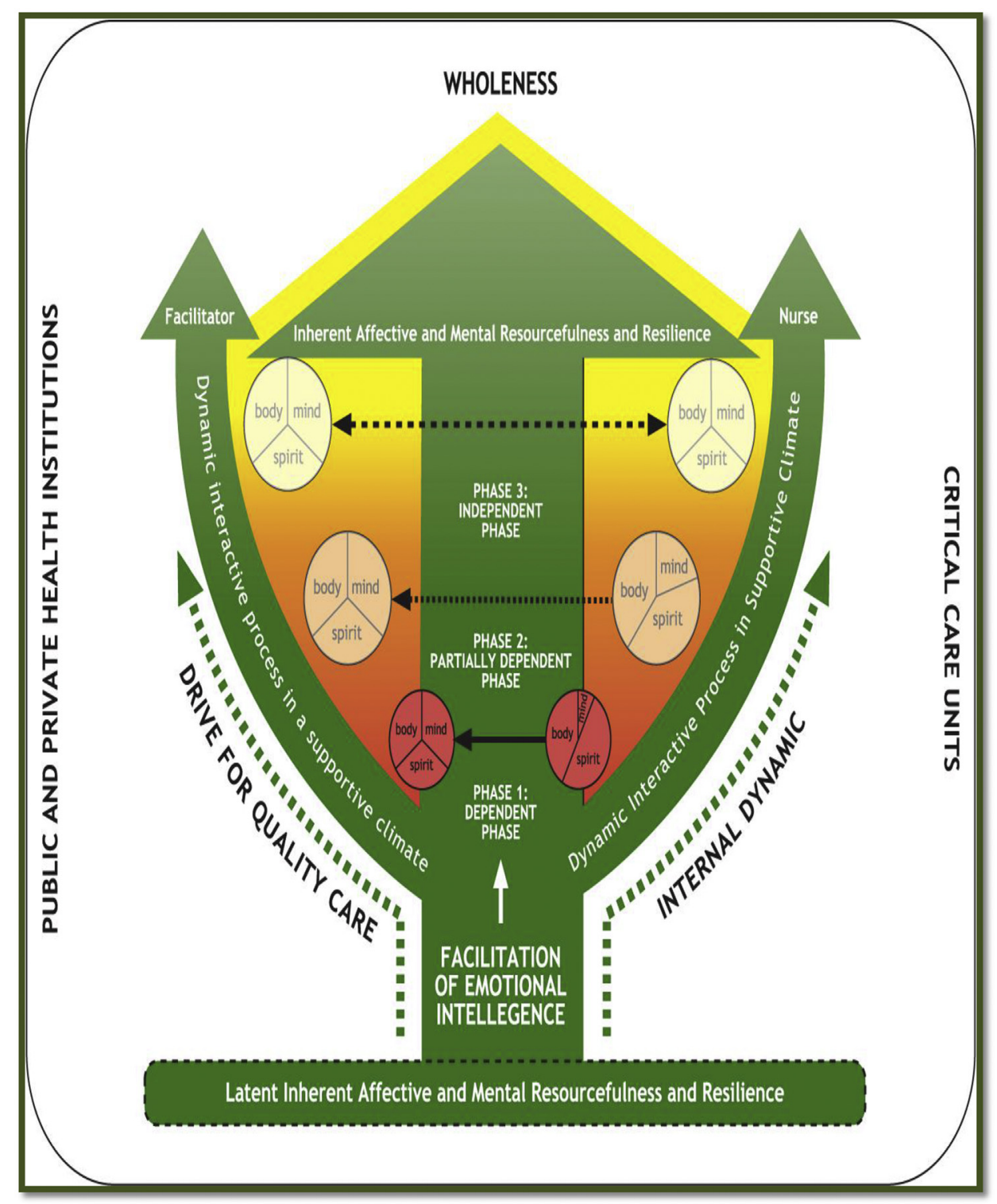

Fig. 1 - Model of the development of the facilitation of EI to promote wholeness of neophyte critical care nurses in South Africa (Towell et al., 2011).

\subsection{Purpose}

The purpose of this model is to provide a framework which facilitates EI to promote wholeness for the neophyte nurse working in critical care in South Africa.

\subsection{Assumptions}

The assumptions on which this model is based are embedded in The Model of the Theory for Health Promotion in Nursing (University of Johannesburg, Department of Nursing, 2009), as discussed below:

- The recipient is a nurse that has recently started to work in a critical care unit in either a private or public hospital. The nurse is seen as a whole person, with an internal and external dimension. The internal dimension consists of body, mind and spirit. He/she functions in an integrated manner with the external environment.

- Due to the stressors of the environment the assumption is made that the recipients have an imbalance in their internal dimensions, as they still need to develop skills to cope with the challenges in the external environment.

- An individual that embodies dimensions of body, mind and spirit and functions in an integrated and interactive manner with the environment is considered whole.

- Wholeness is when there is a balance between the internal dimensions of body, mind and spirit and these dimensions work in an integrated manner with the external environment. 
- Every nurse that commences to work in a critical care unit has an inherent affective and mental resourcefulness and resilience that needs to be developed and to improve their EI.

- The facilitator (the agent) is a mature, professionallyexperienced critical care nurse. The facilitator has developed EI due to experience in critical care and has developed their own unique set of inherent affective and mental resourcefulness and resilience based on the emotional challenges and responses they have faced. The facilitator sees themselves as whole.

- Facilitation is an open dynamic and interactive process that takes place between the facilitator and the nurse and takes place in an open learning environment. The responsibility for learning is shared between the agent and the recipient.

- Emotional intelligence is the individual's ability to be able to identify the emotion that they are feeling and then to be able to change/alter their own emotional state to their advantage. It also involves the ability to recognise an emotion in another person and to be able to use that emotion to motivate or manage people.

- Emotional intelligence is not static and can be improved.

\subsection{Context}

The context of the model is critical care units, which may be in a private or public hospital in South Africa. They may take the form of any discipline of critical care unit, from a specific discipline such as a cardio-thoracic critical care unit to a general critical care unit. The illness acuity levels of the patients can range from low to high depending on the diagnosis of the patient.

\subsection{Definition of central and related concepts}

The following definitions regarding the central and related concepts have been developed by the researchers in order to provide conceptual clarity for the concepts applicable to the model of EI for the facilitation of wholeness within the context of this study. These central and related concepts are the building blocks of this model.

\subsubsection{Facilitation of EI}

Facilitation of EI takes place along a continuum and involves dynamic interaction between the facilitator (agent) and the nurse (the recipient). In the beginning the neophyte nurses are very dependent on the facilitators as they start work in the critical care unit. The nurse moves through each phase with a subtle graduation, as she develops her inherent affective and mental resourcefulness and resilience and ultimately her EI. The nurse has a latent ability to develop affective mental resilience and resourcefulness (Towell, Nel, \& Müller, 2011).

\subsubsection{Facilitation of inherent affective and mental} resourcefulness and resilience

Facilitation of inherent affective and mental resourcefulness and resilience involves enabling improvement of the nurse in a supportive climate. A facilitator helps individuals/groups to accomplish their goals, which takes place in an open learning climate. It is a conscious dynamic and interactive process that takes place over time. The facilitator mobilises resources to enable improvement on a mental, emotional and physical level. Every individual has a pre-existing inherent potential, which can be developed through emotional learning. This potential is essentially a natural ability. Emotional responsiveness can be observed by others. It is the outward manifestation of emotion, feeling or mood and is termed affect. People can see affect through body language. To be able to reason about what is known and what can be observed involves being able to reason critically. It involves being able to intelligently process solutions to problems and then to evaluate the impact of these solutions. A nurse is taught and learns how to adapt and to become resourceful. She develops a set of self-control skills or abilities that allows her to exhibit flexibility and resilience. She uses these skills to bounce back, to use these experiences to survive, to recover and to grow (Towell et al., 2011).

\subsubsection{Dynamic interactive process}

This takes place between the facilitator and the nurse within the critical care unit. The process takes place over a period of time and commences as soon as the nurse begins to work in the critical care unit. It involves interaction between the facilitator and the nurse. In the beginning the nurse is dependent on the facilitator and the communication is mainly one-way but as she develops her inherent affective mental resourcefulness and resilience, the relationship between the facilitator and the nurse becomes more interactive, as the nurse improves her EI and acquires more social skills. Eventually when the nurse has improved her EI and has developed her affective and mental resourcefulness and resilience, the relationship between the nurse and the facilitator changes to one of mutual support (Towell et al., 2011).

\subsubsection{Supportive climate}

The environment within the critical care unit is designed by the senior staff, who are also the facilitators in the unit. The environment is supportive and allows the nurse to develop her own set of self-control skills, improve her EI and enable her to become resourceful and resilient. It is supportive in the fact that nurses are not left alone to nurse a critically ill patient but there is always a facilitator available to work alongside the nurse. After an incident with a patient, for example resuscitation, the facilitator will assist the nurse in reflecting on her emotions and her actions during the resuscitation (Towell et al., 2011).

\subsubsection{Wholeness}

An individual that embodies dimensions of body, mind and spirit and functions in an integrated, interactive manner with the internal and external environment is considered whole (University of Johannesburg, Department of Nursing Science 2009). They function as independent nursing practitioners within the critical care unit and in an integrated and interactive manner within the stated environment. 


\section{A structural description of the model}

Fig. 1 represents a structural representation of the model of EI for the facilitation of wholeness in critical care nurses in South Africa and will serve as the basis for the ensuing discussion and explanations.

The main feature of the model is the facilitator, who plays a central role in advancing the EI of the nurse that commences work in a critical care unit for the first time, to achieve balance in body, mind and spirit. The structure of the model and the overall form will be described as proposed by Chinn and Kramer (2011). The model is composed of different shapes and colours, all of which have a significant meaning; an explanation of these will also be included in the description.

There are three phases in the model: the dependent phase, the partially dependent phase and the independent phase. The outer lines of the model depict the critical care environment and its uniqueness. They signify the supportive environment that is created by the facilitators, through a dynamic interactive process between the nurse and the facilitator. Each nurse has a latent inherent affective and mental resourcefulness and resilience that can develop through the process of facilitation of EI of the nurse by the facilitator. The outer lines are green as this symbolises newness and growth (Smith, 2010a). The supportive environment is green as it represents the newness of the nurse entering into a critical care unit, as well as the potential for growth of the nurse.

The broken lines that begin at the base on either side of the process of facilitation of EI signify the dynamics of the model. The arrows at the top of each line signify its continuation throughout the process of facilitation. The broken line and arrow on the left-hand side indicate the dynamics of the healthcare institution that aims for quality nursing care, which is driven by the facilitator. The broken line and arrow on the right-hand side of the model signify the nurse's internal dynamic and desire for knowledge and her quest for wholeness.

The process of facilitation of EI starts as soon as the nurse enters the critical care unit and continues throughout the three phases. The aim of the facilitation of EI is for the nurse to gain balance in her internal environment, specifically the dimension of the mind, to develop affective and mental resourcefulness and resilience, so that she can progress towards achieving wholeness in body mind and spiritual dimensions, which is the ultimate goal.

The external border of the model signifies the context of the model, which are the critical care units in South Africa. The arms of the model signify the dynamic interactive and supportive climate. The inside of the model demonstrates the relationship that develops between the nurse and the facilitator throughout the three phases of the model. The circles on the left side depict the internal environment of the facilitator. The inside of the circle is divided equally into portions of body, mind and spirit; which provides evidence that the facilitator has achieved a balance in her internal environment. The circles representing the facilitator fade in each phase. This represents the intensity of the relationship between the nurse and the facilitator and shows that the intensity decreases as the nurse develops her own affective and mental resourcefulness and resilience skills and EI.
The three circles on the right-hand side demonstrate the internal dimension of the nurse during the three phases of the model. They demonstrate that the nurse begins with an imbalance in her internal environment of mind, as this is the least developed, but as she moves through the various phases with the facilitation of EI she begins to find balance within her internal dimension of mind.

The line that connects the circles representing the facilitator and the nurse demonstrate the dependent relationship between the facilitator and the nurse during each phase of the model. They will be explained in more detail during the description of each phase.

\subsection{The process of the model}

The three sequential phases in which the process of EI for the facilitation of wholeness in critical care nurses takes place are:

Phase 1. The dependent phase

Refer to Fig. 1, which depicts the dependent phase of the model. The nurse that starts work in a critical care unit for the first time has a latent inherent affective and mental resourcefulness and resilience that can develop through the process of the facilitation of EI. In phase 1 the nurse starts work in a critical care unit, and has a quest for knowledge and for wholeness.

The broken lines that begin at the base on either side of the process of facilitation of EI signify the dynamics of the model. The arrows at the top of each line signify its continuation throughout the process of facilitation. The broken line and arrow on the left-hand side indicate the dynamics of the healthcare institution that aims to achieve quality nursing care. The broken line and arrow on the right-hand side of the model signify the registered nurse's internal dynamic and desire for knowledge and quest for wholeness.

The process of facilitation of EI is dynamic and interactive. This process begins on the first day that the nurse begins work in the critical care unit and continues throughout her development and his/her quest for wholeness. The nurse is introduced to the facilitator when he/she begins work in the critical care unit, and during this phase the nurse is very dependent on the facilitator. The circles of the facilitator and nurse are in close proximity to each other, demonstrating the nurse's dependence on the facilitator. The solid line that joins the facilitator to the nurse depicts the dependency that the nurse has on the facilitator; this is also depicted by the one-way arrow pointing to the facilitator. At this time the nurse can offer no emotional support to the facilitator within the critical care environment, as her skills are not yet developed.

Each individual comprises three internal dimensions: a body, mental aspect or mind and a spiritual aspect. The dimension of mind contains the emotional and mental dimensions of the person. This is evidenced by the circles in the first phase that contain these three dimensions. The facilitator has developed a balance in her internal dimensions. During this phase the nurse is challenged by her dimension of mind. The mental portion of the circle is the smallest, as it is the least developed. The nurse is yet to develop her set of affective and mental resourcefulness and resilience skills to be able to cope with the new challenges she will face. The 
challenges that the nurse is faced with may be positive, but many have the potential to be negative. She is faced with challenges, change and negative emotion on an almost daily basis. She is at the beginning of her professional journey in the critical care environment and is yet to find the skills to manage her affective and mental challenges.

The background colour of this phase is red, and it symbolises strong emotions rather than intellectual ideas at this time (Anime, 2001). Red is also recognised as a stimulant and it draws attention (Smith, 2010a). In this case the affective and mental dimension is acting as the primary stimulant and is drawing the attention of the nurse, so she cannot find balance.

The facilitator is the mature, experienced critical care nurse and is there to guide the nurse through the emotions and challenges she is faced with, to help her develop a set of skills in order to cope with the emotional responsibilities that she will face. The facilitator will commence the process of facilitation by orientating the nurse to the critical care environment on her first day and forming a relationship between the nurse and herself and by creating a supportive environment for the nurse to work in.

This facilitation process is a dynamic interactive process that takes place between the nurse and the facilitator. They both have a shared responsibility for the nurse's learning and development of her resourcefulness and resilience.

There is a subtle graduation into phase two and there is no cut-off where the nurse moves into the next phase. A shift takes place in the internal balance of the nurse; hence the colour change is graduated from red to orange. With facilitation there is a gradual change in her internal self - the mental portion begins to demand less energy as the nurse begins to develop her latent inherent affective and mental resourcefulness and resilience skills. As they develop, the nurse gradually moves into the next phase.

Phase 2. The partially dependent phase

The partially dependent phase is demonstrated in Fig. 1. The process of the facilitation of EI continues. The facilitator and the nurse are still working during this phase within the dynamic and supportive climate, as depicted by the continuation of the arms.

The colour orange signifies energy, warmth, enthusiasm and the need for attention (Smith, 2010b). The facilitator is using her energy in the nurturing of the nurse - as a gradual process. The nurse is also using her energy in working at acquiring new knowledge and skills, to be able to manage her affective and mental challenges. She is enthusiastic in facing her challenges and demands attention to help her cope with the challenges she faces. The facilitator during this stage is also enthusiastic in being able to assist the nurse, as she begins to manage the challenges she is faced with, to develop her inherent affective and mental resourcefulness and resilience.

The facilitator and the nurse move more apart, as depicted by the circles representing the inner dimension of the facilitator and the nurse. This demonstrates that the nurse is in the process of developing her own set of self-control skills and improving her EI under the guidance and facilitation of the facilitator. She becomes less dependent on the facilitator as her own skills develop. The facilitator guides the nurse during this phase but the nurse takes more control over her own learning of skills to improve her affective and mental resilience and resourcefulness. This is also depicted by the broken line that joins the facilitator to the nurse. The line is broken but the gaps are still close together to reflect that the nurse is still dependent on the facilitator for some things, even though her skills are increasing. The arrow is still pointing from the nurse to the facilitator, as the nurse is still dependent on the facilitator and at this time she is not yet able to support the facilitator emotionally within the critical care environment, as she is in the process of developing her skills.

The nurse gains more of a balance between body, mind and spirit dimensions, as she manages to develop latent inherent affective and mental resourcefulness and resilience skills to help her cope with the affective and mental challenges that she faces. Developing these skills helps the nurse to move closer to obtaining affective mental resilience and resourcefulness. The size of the mental dimension increases as she begins to find more balance.

There is no cut-off to this phase or time frame. The nurse moves at her own pace as she develops her own set of unique inherent skills. The background colour begins to change gradually from orange to yellow.

\section{Phase 3. The independent phase}

The background colour in phase three is yellow and this signifies that the nurse shines with optimism, enlightenment and happiness (Smith, 2010c). It symbolises the promise of a positive future. She has developed her inherent affective and mental resourcefulness and has developed resilience to the continuing challenges that she may face.

The central arrow head symbolises the transformation, courage and change of the nurse. She has moved more towards achieving wholeness as she has increased her knowledge and skills and has found balance in her internal environment of body, mind and spirit. Her quest for personal and professional wholeness is lifelong, because she can never have enough knowledge within the critical care environment. However, she has developed her inherent set of unique skills that allow her to cope affectively and mentally using the resources she has developed through the challenges she faces, thereby enabling her to focus on her quest for knowledge, wholeness and resiliency. The circle that depicts the facilitator has moved with her throughout the three phases, demonstrating the supportive relationship that has formed between the facilitator and the nurse.

This phase also includes a dynamic interactive process, as now the nurse has become the mature critical care nurse. The line between the facilitator and nurse is still present as they continue to support each other as colleagues, but the gaps are further apart, demonstrating that the nurse is an independent practitioner. The arrows on the line now depict two-way communication between the nurse and the facilitator, since they are now colleagues who support each other.

\subsection{A description of the guidelines for operationalising the model}

Broad guidelines were developed for operationalising the model of facilitation of EI to promote wholeness of neophyte 
critical care nurses within the context of both public and private healthcare in South Africa. The research findings and literature were used as the base for formulation of the guidelines. For each phase of the model broad outlines were developed, each guideline has its own operational implications.

\subsection{Evaluation of the model}

This model was critically evaluated by a panel of 11 experts. Six of the experts had doctoral degrees (five in nursing science and one in education), most of which were experts in the field of theory generation. There were two doctoral students on the panel. There were two experts from clinical practice and they were trained critical care nurses and shift leaders in critical care. The remaining member of the panel was a representative from the community who was a psychiatric nurse with a private counselling practice. The evaluation criteria proposed by Chinn and Kramer (2011) - clarity, simplicity, scope and purpose, accessibility and clinical significance - were used to evaluate the model. There was consensus amongst the experts on each criteria that the model fulfilled the six criteria as proposed by Chinn and Kramer (2011).

\subsection{Limitations}

This model has not been scientifically tested and further research is needed on the model.

\section{Conclusion}

The discussion above provides a description of the steps that were utilised in the development of the model of EI for the facilitation of wholeness in critical care nurses. These steps included distilling and analysis of the central concepts, placing the concepts in relationships, and the description of the model.

The EI of the registered nurses that work in critical care units in South Africa was investigated and described. The facilitation of affective and mental resourcefulness and resilience to improve EI within nursing is a new, important and fascinating challenge. The development of these skills and EI takes time and patience.

It is recommended that the model can be implemented in any critical care unit in South Africa. It has value in guiding the actions of facilitators, shift leaders, unit managers and nursing service managers to facilitate emotional intelligence to promote wholeness of the neophyte registered nurse that commences work in a critical care unit. It is recommended that the facilitators be identified from the senior registered nurses within each unit and that they agree to assume responsibility of being facilitators of nurses as they start working in critical care units. This will ensure that each nurse, as they commence work, will be assigned to a specific facilitator or a team of facilitators that they will work with from their first day. This will ensure that a dynamic interactive relationship develops between the facilitator/s and the nurses, so that the facilitation of the EI of the nurses becomes and is maintained as a priority until the development of their affective and metal resourcefulness and resilience. Hopefully this will have a positive impact on the quality of patient care, wholeness of the nurse, attrition/ turnover rate of staff, as well as staff satisfaction within critical care units.

It is recommended that further research on the current model be encouraged, so that refinement and adjustment in practice can take place.

This model can be utilised within nursing education in order to develop the affective and mental resourcefulness and resilience and improve the EI of new nurses that are commencing training in nursing education programmes.

\section{R E F E R E N C E S}

Anime, M. (2001). Symbolism colors. Available from http://www. three-musketeers.net/mike/colors.html Accessed 01.11.10.

Chinn, P. L., \& Kramer, M. K. (2011). Integrated theory and knowledge development in nursing (7th ed.). St Louis: Mosby Elsevier.

Dickoff, J., James, P., \& Wiedenbach, E. (1968). Theory in a practice discipline - Part 1: practice oriented theory. Nursing Research, 17(5), 415-435.

Kaur, D., Sambasivan, M., \& Kumar, N. (2013). Effect of spiritual intelligence, emotional intelligence, psychological ownership and burnout on caring behavior of nurses: a cross-sectional study. Journal of Clinical Nursing, 22(21-22), 3192-3202.

Kooker, B. M., Shoultz, J., \& Codier, E. E. (2007). Identifying emotional intelligence in professional nursing practice. Journal of Professional Nursing, 23(1), 30-36.

Matthews, G., Zeidner, M., \& Roberts, R. D. (2004). Emotional intelligence science and myth (pp. 468-485). Massachusettes: Instituet of Technology.

McGill, B. H., n.d., Brainyquotes, viewed 11 September 2014, from http://www.brainyquote.com/quotes/quotes/b/ bryanthmc168216.html.

Meltzer, L. M., \& Huckabay, L. M. (2004). Critical care nurses' perception of futile care and its effect on burnout. American Journal of Critical Care, 13(3), 202-204.

Newman, M. (1994). Health as expanding consciousness. Boston: Jones and Bartlett.

Petrides, K. V. (2006). Internal consistency data for the TEIQue and TEIQUeSF (v.1.50), Trait Emotional Intelligence Research Programme. Available from http://www.ioe.ac.uk/schools/phd/ kpetrides/teiquel.htm Accessed 07.07.09.

Poncet, M. C., Toullic, P., Papazian, L., Kentish-Brown, N., Timsit, J. F., Pochard, F., et al. (2007). Burnout syndrome in critical care nursing staff. American Journal of Respiratory Critical Care Medicine, 175, 698-704.

Smith, K. (2010a). A glimpse into the meaning, symbolism and psychology of color. All about the colour red, how the colour red affects us physically. Available from http://www. sensationalcolor.com Accessed 05.11.10.

Smith, K. (2010b). A glimpse into the meaning, symbolism and psychology of color. All about the colour orange, how the colour orange affects us physically. Available from http://www. sensationalcolor.com Accessed 05.11.10.

Smith, K. (2010c). A glimpse into the meaning, symbolism and psychology of color. All about the colour yellow, how the colour yellow affects us physically. Available from http://www. sensationalcolor.com Accessed 05.11.10.

Towell, A. J., Nel, W. E., \& Müller, A. (2011). Model of emotional intelligence for the facilitation of wholeness of critical care nurses in 
South Africa. unpublished doctoral thesis. Johannesburg:

Department of Nursing Science, University of Johannesburg.

Towell, A. J., Nel, E., \& Muller, A. (2013). The emotional

intelligence of a group of critical-care nurses in South Africa.

Heatlth SA Gesondheid, 1891. Art.\#674, 10 pages http://dx.doi. org/10.4102/hsag.v18i1.674.

Trait Emotional Intelligence Research Programme. (2001). TEIQue version 1.50. Available from http://www.psychometriclab. com/admins/files/TEIQue\%20interpretations.pdf Accessed 07.07.09.
University of Johannesburg. Department of Nursing Sciences. (2009). Paradigm. Johannesburg.

Vitello-Cicciu, J. M. (2003). Innovative leadership through emotional intelligence. Nursing Management, 34(10), 203-210.

Walker, L. O., \& Avant, K. C. (2005). Strategies theory construction in nursing (4th ed.). New Jersey: Pearson Education Inc.

Walker, L. O., \& Avant, K. C. (2011). Strategies theory construction in nursing (3rd ed.). Norwalk: Appleton and Lange. 